\title{
Assessment of depression and anxiety in adult cancer outpatients: a cross-sectional study
}

\author{
Nauman A Jadoon ${ }^{1 *}$, Waqar Munir ${ }^{2}$, Mohammad A Shahzad $^{1}$, Zeshan S Choudhry ${ }^{1}$
}

\begin{abstract}
Background: The prevalence of anxiety and depressive disorders in cancer patients and its associated factors in Pakistan is not known. There is a need to develop an evidence base to help introduce interventions as untreated depression and anxiety can lead to significant morbidity. We assessed the prevalence of depression and anxiety among adult outpatients with and without cancer as well as the effect of various demographic, clinical and behavioral factors on levels of depression and anxiety in cancer patients.

Methods: This cross-sectional study was carried out in outpatient departments of Multan Institute of Nuclear Medicine and Radiotherapy and Nishtar Medical College Hospital, Multan. Aga Khan University Anxiety and Depression Scale (AKUADS) was used to define the presence of depression and anxiety in study participants. The sample consisted of 150 diagnosed cancer patients and 268 participants without cancer (control group).

Results: The mean age of cancer patients was 40.85 years $(S D=16.46)$ and median illness duration was 5.5 months, while the mean age of the control group was 39.58 years $(S D=11.74)$. Overall, $66.0 \%$ of the cancer patients were found to have depression and anxiety using a cutoff score of 20 on AKUADS. Among the control group, 109 subjects (40.7\%) had depression and anxiety. Cancer patients were significantly more likely to suffer from distress compared to the control group $(\mathrm{OR}=2.83,95 \% \mathrm{Cl}=1.89-4.25, \mathrm{P}=0.0001)$. Performing logistic regression analysis showed that age up to 40 years significantly influenced the prevalence of depression and anxiety in cancer patients. There was no statistically significant difference between gender, marital status, locality, education, income, occupation, physical activity, smoking, cancer site, illness duration and mode of treatment, surgery related to cancer and presence of depression and anxiety. Cancers highly associated with depression and anxiety were gastrointestinal malignancies, chest tumors and breast cancer.

Conclusions: This study highlights high prevalence rates of depression and anxiety in cancer patients. Younger age was associated with a higher likelihood of meeting criteria for psychological morbidity. The findings support screening patients for symptoms of depression and anxiety as part of standard cancer care and referring those at a higher risk of developing psychological morbidity for appropriate care.
\end{abstract}

\section{Background}

Cancer is a serious and potentially life-threatening illness which has an effect on physical and emotional well being of patients and their families. The diagnosis of cancer is a stressful event causing significant psychological distress [1-4]. In this era of improved cancer care, it is still often believed that pain and death is inevitable for cancer patients [5].

Various studies have demonstrated high levels of depression and anxiety in cancer patients using a variety

\footnotetext{
* Correspondence: dr.naumanjadoon@gmail.com

'Department of Medicine, Nishtar Medical College Hospital, Multan, Pakistan Full list of author information is available at the end of the article
}

of assessment methods $[1,3,4,6-8]$. Depression is a challenge to study in cancer patients as symptoms occur over a range of spectrum being different in different patients $[4,9]$. It is a challenging job to diagnose depression in patients with cancer. It may present with guilt, worthlessness, hopelessness, lowered self esteem, social withdrawal or suicidal preoccupation $[9,10]$. This is further complicated by the findings that symptoms in cancer patients occur in clusters [11]. Anxiety has been shown to frequently coexist with depressive disorders [6-9]. This is significant as it has been shown that patients with comorbid anxiety and depressive disorders tend to have severe symptoms, longer recovery times, poorer outcomes and 
greater use of healthcare resources than those with a single disorder [12]. Prevalence and severity of psychological distress also vary across cancer types $[3,4]$. Anxiety and depression in cancer patients may be caused by various reasons including psychological reaction caused by diagnosis of cancer, long duration of treatment, side effects of treatment, repeated hospitalizations, disruption in life and diminished quality of life $[6,13,14]$. Furthermore, some of the agents act directly on central nervous system causing psychiatric morbidity [15].

Despite all these findings of higher likelihood of cancer patients to suffer from psychological distress, studies have reported that healthcare workers fail to identify cancer patients with depression and anxiety leading to under-treatment in $40-90 \%$ of the cases $[10,16,17]$. It is important to recognize depression in cancer patients because it may reduce chances of survival and predict early mortality $[18,19]$. Presence of depression and anxiety produces complications in treatment of both cancer and depression and can lead to poor compliance with treatment resulting in worsening of situation. It puts the patients at a higher risk of suicide and may produce a desire for hastened death [20]. Depression leads to a decline in patient satisfaction with medical care and predicts disease progression $[21,22]$. Psychological distress also has a negative effect on quality of life [23]. Depression and anxiety impair quality of life not only of the patients but also of their caregivers [24,25]. Research suggests that interventions to treat depression and anxiety are effective even in patients with advanced disease $[13,26]$. In addition, identification and treatment of depression and anxiety leads to reduction in disease progression improvement in survival rates, reduction in healthcare costs and improvement in quality of life $[18,19,22,23,27]$.

There is a need to develop an evidence base to help introduce interventions as untreated depression and anxiety can lead to significant morbidity. We need prevalence estimates to be able to develop an effective strategy. Although there are a number of studies assessing psychological distress in cancer patients, there are significant gaps in literature. Majority of studies have not used a control group. This may limit generalizability of such studies due to recruitment bias. Furthermore, we have not been able to find studies investigating the association of various demographic, behavioural and clinical factors with the prevalence of depression and anxiety in cancer patients. Such studies are needed so as to identify subgroups needing intervention. Finally, there is paucity of studies on psychological distress in cancer patients from this region. There is only one study on the prevalence of depression and anxiety from Pakistan which employs a small sample size from a single centre with no control group [28]. This is the first multi-centre study from Pakistan with adequate number of patients reporting the prevalence of depression and anxiety in adult cancer outpatients. This paper outlines the results of a cross-sectional study carried out in the outpatient departments of Multan Institute of Nuclear Medicine and Radiotherapy (MINAR) and Nishtar Medical College Hospital, Multan (NMCH). The main objective of our study was to determine the prevalence of depression and anxiety in patients with cancer using a validated and reliable screening instrument and to compare them with the patients visiting medical outpatient department. We also wanted to find out the relationship of depression and anxiety with age, gender, locality, education, income and occupation, type of cancer, current treatment modality, duration of illness and history of surgical intervention related to the disease, smoking and physical activity.

\section{Methods}

A multi-centre, cross-sectional study was carried out in the outpatient departments of MINAR and $\mathrm{NMCH}$, Multan to determine the prevalence of depression and anxiety in adult cancer outpatients. Consecutive patients visiting outpatient department were recruited for the study. Patients were included if they had a cancer diagnosis, were in the age range 18-70 years, consented to participate in the study, and were able to complete questionnaire. Exclusion criteria were diagnosis at current visit, critical condition, language or hearing problem, cognitive impairment, incomplete records or ongoing psychological treatment. The authors approached all the eligible patients and requested their consent to participate in the study after explaining the study. Controls were randomly selected from different outpatient departments of the same centres to reduce potential differences in socioeconomic and educational factors. Every fifth patient visiting the medical outpatient department was recruited in the study after taking informed consent.

Anxiety and depression were assessed using a self administered structured questionnaire. The questionnaire was administered after taking written informed consent from the participants. Data on basic demographic details including age, gender, locality, education, income and occupation were collected. Cancer related variables including type of cancer, current treatment modality, duration of illness and history of surgical intervention related to the disease were obtained from the medical record of the patients. Behavioral factors included in the questionnaire to determine their association with depression and anxiety were smoking and physical activity which were self reported. Patients were labelled smokers if they had smoked for more than one year. Physical activity was defined as exercise for more 
than 3 hours per week. Anxiety and depression was assessed using Aga Khan University Anxiety and Depression Scale (AKUADS). It is a 25 -item self administered instrument that measures the presence of symptomatology of anxiety and depression in adults. It is a widely used instrument developed indigenously in Urdu. Its validation study has shown that it is a reliable and valid instrument to assess psychological morbidity in patients. It has 13 psychological and 12 somatic items which measure presence and severity of symptoms making it superior to other available instruments in Urdu containing only either psychological or somatic items $[29,30]$. At a cut-off score of 20 , it has a sensitivity of $66 \%$, a specificity of $79 \%$, a positive predictive value of 83 and a negative predictive value of 60 . It has a good level of reliability and analysis showed item-item correlation $\geq 0.75[29,30]$. The data from the questionnaire was entered as categorical data on the basis of cutoff for analysis.

Data was analyzed using Statistical Package for Social Sciences 16 (SPSS Inc., Chicago, IL, USA). Descriptive analyses were recorded as means and proportions. Logistic regression analysis was employed to determine the association of various demographic, clinical and behavioral factors with the presence of depression and anxiety in cancer patients. A p value of $<0.05$ was considered statistically significant.

The study was approved by ethics review committee of $\mathrm{NMCH}$, Multan. Written informed consent was obtained from all the participants accrued in the study.

\section{Results}

Out of a total of 200 cancer patients selected, 186 were determined to be eligible for survey. Fourteen patients were ineligible on account of diagnosis on recent visit (4), critical condition (1), cognitive impairment (4), language problem (2) or ongoing psychiatric treatment (3). With a response rate of $90.9 \%, 169$ patients consented to participate in the study and completed questionnaires. After excluding incompletely filled questionnaires, 150 participants were included in final analysis. The mean age of cancer patients was 40.85 years $(\mathrm{SD}=16.46$ years $)$ and median duration of illness was 5.50 months. Majority of the patients were male (64.0\%), married (79.3\%), from urban locality (53.3\%), illiterate (44.0\%), belonging to low socioeconomic group (66.7\%), and unemployed (29.3\%). Most of the patients were non-smokers (71.3\%) and physically active $(56.0 \%)$. The most common diagnoses were urological (21.3\%), hematological (18.0\%), and head and neck malignancies (15.0\%) and breast (14.0\%) cancer. A control group of 300 individuals was selected out of which 293 were eligible for accrual. In total, 281 subjects consented and filled the study questionnaire with a response rate of $95.9 \%$. Control subjects included in the
Table 1 Participant Characteristics

\begin{tabular}{|c|c|c|}
\hline Variables & $\begin{array}{c}\text { Cancer Subjects } \\
\text { No. (\%) }\end{array}$ & $\begin{array}{c}\text { Control Subjects } \\
\text { No. (\%) }\end{array}$ \\
\hline \multicolumn{3}{|l|}{ Age } \\
\hline$\leq 40$ Years & 78(52.0) & 166(61.9) \\
\hline$>40$ Years & $72(48.0)$ & 102(38.1) \\
\hline \multicolumn{3}{|l|}{ Gender } \\
\hline Male & $96(64.0)$ & $158(59.0)$ \\
\hline Female & $54(36.0)$ & $110(41.0)$ \\
\hline \multicolumn{3}{|l|}{ Marital Status } \\
\hline Married & $119(79.3)$ & 193(72.0) \\
\hline Unmarried & $31(20.7)$ & $75(28.0)$ \\
\hline \multicolumn{3}{|l|}{ Locality } \\
\hline Urban & $80(53.3)$ & 139(51.9) \\
\hline Rural & $70(46.7)$ & 129(48.1) \\
\hline \multicolumn{3}{|l|}{ Education } \\
\hline Illiterate & $60(40.0)$ & $80(29.9)$ \\
\hline Primary & 19(12.7) & $42(15.7)$ \\
\hline Secondary & $31(20.7)$ & $68(25.4)$ \\
\hline High School Certificate & 19(12.7) & $40(14.9)$ \\
\hline Bachelor & 17(11.3) & $23(8.6)$ \\
\hline Masters & $4(2.7)$ & $15(5.6)$ \\
\hline \multicolumn{3}{|l|}{ Income } \\
\hline$<$ Rs. 10,000 & $100(66.7)$ & $147(54.9)$ \\
\hline Rs. $10,000-$ Rs. 20,000 & $41(27.3)$ & $50(18.7)$ \\
\hline Rs.20,000-Rs.40,000 & $6(4.0)$ & $43(16.0)$ \\
\hline$>$ Rs. 40,000 & $3(2.0)$ & $28(10.4)$ \\
\hline \multicolumn{3}{|l|}{ Occupation } \\
\hline Professional & $13(8.7)$ & $20(7.5)$ \\
\hline Skilled worker & $10(6.7)$ & $29(10.8)$ \\
\hline Administrative Job & $11(7.3)$ & $23(8.6)$ \\
\hline Sales & $19(12.7)$ & $55(20.5)$ \\
\hline Farming & $24(16.0)$ & $12(4.5)$ \\
\hline Unskilled/Elementary & $29(19.3)$ & $31(11.6)$ \\
\hline Unemployed & $44(29.3)$ & $98(36.6)$ \\
\hline \multicolumn{3}{|l|}{ Physical Activity } \\
\hline Active & $84(56.0)$ & \\
\hline Inactive & $66(44.0)$ & \\
\hline \multicolumn{3}{|l|}{ Smoking } \\
\hline Smoker & $43(28.7)$ & \\
\hline Non-Smoker & 107(71.3) & \\
\hline \multicolumn{3}{|l|}{ Cancer } \\
\hline Hematological & $27(18.0)$ & \\
\hline Head \& Neck & $23(15.3)$ & \\
\hline Urological & $32(21.3)$ & \\
\hline Breast & $21(14.0)$ & \\
\hline Chest & $13(8.7)$ & \\
\hline Sarcoma & $11(7.3)$ & \\
\hline Squamous \& Basal Cell & $1(0.7)$ & \\
\hline
\end{tabular}


Table 1 Participant Characteristics (Continued)

\begin{tabular}{ll}
\hline Brain & $7(4.7)$ \\
\hline GIT & $15(10.0)$ \\
\hline Duration & \\
\hline$\leq 6$ Months & $88(58.7)$ \\
\hline$>6$ Months & $62(41.3)$ \\
\hline Treatment & $55(36.7)$ \\
\hline Chemotherapy & $22(14.7)$ \\
\hline Radiotherapy & $59(39.3)$ \\
\hline Concomitant & $14(9.3)$ \\
\hline None & \\
\hline Surgery & $63(42.0)$ \\
\hline Yes & $87(58.0)$ \\
\hline No
\end{tabular}

final analysis were 268 who had completely filled out questionnaires. The mean age of control group was 39.58 years $(S D=11.74$ years). Demographics and clinical characteristics of cancer subjects are presented in table 1 along with demographics of control group. Since the control group accrual was done from waiting rooms of medical outpatient department, data about their diagnoses is not available.

Overall, $66.0 \%$ of the cancer patients were found to have depression and anxiety using a cut-off score of 20 on AKUADS. Among the control group, 109 subjects (40.7\%) had depression and anxiety. This difference in the prevalence rates was found to be statistically significant $(\mathrm{p}<0.001)$. Cancer patients were 2.83 times more likely to have psychological distress $(95 \% \mathrm{CI}=1.89$ 4.25). Cancers with the highest prevalence of depression and anxiety were gastrointestinal malignancies, chest tumors and breast cancer.

Table 2 describes the results of logistic regression analysis performed for determining the association of various demographic, clinical and behavioral factors with the presence of depression and anxiety in cancer patients. Age less than 40 years was found to significantly increase the odds of having depression and anxiety among cancer patients. The findings showed that among different demographic variables, there were no significant differences among anxiety, depression and patients' gender, marital status, locality, educational background, socioeconomic status, and occupation. The results also indicated that type of malignancy, duration of illness, type of intervention and surgery related to disease did not significantly alter the odds of having depression and anxiety. Finally among behavioral factors, both smoking and physical activity did not significantly alter the odds of suffering from depression and anxiety.
Table 2 The Results of Logistic Regression Analysis showing association of variables with Psychological distress in cancer patients

\begin{tabular}{|c|c|c|c|}
\hline Variables & OR & $95 \% \mathrm{Cl}$ & $\mathbf{P}$ \\
\hline Age & & & 0.027 \\
\hline$\leq 40$ Years & 1 & & \\
\hline$>40$ Years & 0.46 & $0.23-0.91$ & \\
\hline Gender & & & 0.900 \\
\hline Male & 1 & & \\
\hline Female & 1.05 & $0.52-2.12$ & \\
\hline Marital Status & & & 0.297 \\
\hline Married & 1 & & \\
\hline Unmarried & 0.65 & $0.29-1.46$ & \\
\hline Locality & & & 0.534 \\
\hline Urban & 1 & & \\
\hline Rural & 1.24 & $0.63-2.45$ & \\
\hline
\end{tabular}

\begin{tabular}{lcl}
\hline Education & & \\
\hline Illiterate & 1 & \\
\hline Primary & 0.5 & $0.07-3.81$ \\
\hline Secondary & 0.27 & $0.03-2.53$ \\
\hline High School Certificate & 0.63 & $0.08-5.10$ \\
\hline Bachelors & 0.73 & $0.08-6.31$ \\
\hline Masters & & $0.05-3.84$
\end{tabular}

\begin{tabular}{lcc}
\hline Income & & \\
\hline$<$ Rs. 10,000 & 1 & \\
\hline Rs. $10,000-$ Rs. 20,000 & 0.27 & $0.02-3.08$ \\
\hline Rs.20,000-Rs.40,000 & 0.21 & $0.02-2.5$ \\
\hline$>$ Rs. 40,000 & 0.25 & $0.01-4.73$ \\
\hline
\end{tabular}

\begin{tabular}{ll}
\hline Occupation & 0.714
\end{tabular}

\begin{tabular}{lll}
\hline Professional & 1 & \\
\hline Skilled worker & 0.48 & $0.12-1.98$ \\
\hline Administrative Job & 0.68 & $0.15-2.99$ \\
\hline Sales & 1.91 & $0.50-7.23$ \\
\hline Farming & 0.57 & $0.17-1.86$ \\
\hline Unskilled/Elementary & 0.79 & $0.28-2.25$ \\
\hline Unemployed & 0.72 & $0.27-1.93$
\end{tabular}

\begin{tabular}{|c|c|c|c|}
\hline Physical & & & 0.397 \\
\hline Active & 1 & & \\
\hline Inactive & 1.35 & $0.68-2.67$ & \\
\hline
\end{tabular}

\begin{tabular}{lccc}
\hline Smoker & 1 & 0.747 & \\
\cline { 1 - 2 } Non-Smoker & 0.49 & $0.22-1.00$ & \\
\hline Cancer & & & \\
\hline Hematological & 1 & & \\
\cline { 1 - 3 } Head \& Neck & 7.0 & $1.32-37.15$ \\
\hline Urological & 3.47 & $0.62-19.33$ \\
\hline Breast & 3.9 & $0.75-20.34$ \\
\hline Chest & 2.03 & $0.34-12.24$ \\
\hline
\end{tabular}


Table 2 The Results of Logistic Regression Analysis showing association of variables with Psychological distress in cancer patients (Continued)

\begin{tabular}{|c|c|c|c|}
\hline Sarcoma & 5.42 & $0.04-60.77$ & \\
\hline Squamous \& Basal Cell & 5.41 & $0.81-36.36$ & \\
\hline Brain & 1.24 & $0.23-6.62$ & \\
\hline GIT & 8.67 & $1.05-71.57$ & \\
\hline Duration & & & 0.747 \\
\hline$\leq 6$ Months & 1 & & \\
\hline$>6$ Months & 1.12 & $0.56-2.22$ & \\
\hline Treatment & & & 0.995 \\
\hline Chemotherapy & 1 & & \\
\hline Radiotherapy & 0.95 & $0.28-3.24$ & \\
\hline Concomitant & 0.84 & $0.20-3.46$ & \\
\hline None & 0.92 & $0.27-3.12$ & \\
\hline Surgery & & & 0.234 \\
\hline Yes & 1 & & \\
\hline No & 0.66 & $0.33-1.32$ & \\
\hline
\end{tabular}

\section{Discussion}

The main finding of this study is the high prevalence of depression and anxiety in cancer patients as compared to the control group (66.0\% vs. $40.7 \%)$. In our study, $66 \%$ patients with cancer had depression and anxiety. This is slightly higher than some studies conducted earlier which reported prevalence of depression spectrum syndromes ranging from $0-58 \%[1,3,4]$. However, the findings are comparable to a recent study from Pakistan reporting prevalence rates of $52 \%$ in cancer patients and a study from Iran showing rates of $47.2 \%$ and $57 \%$ for depression and anxiety respectively [28,31]. There can be a number of reasons for this difference in prevalence rates. A first explanation could be that most of the studies on prevalence of psychological morbidity in cancer patients are from developed countries which have low prevalence of mental health problems as compared to developing countries [32]. A second explanation could be that prevalence of psychological morbidity even in general population of Pakistan is much higher, as documented by a systematic review reporting prevalence rate of $34 \%$ in general population which is close to the level of psychological morbidity in control group in our study [33]. A third explanation could be that many of the participants in our study were from rural areas, illiterate, and had a low household income which is established risk factors for psychiatric morbidity [28]. Also the prevailing situation in the country puts them at even higher risk as country is facing socio-political instability, economic crises and growing unemployment.

This is the first study to our knowledge from Pakistan reporting depression and anxiety in cancer patients from two centres with a control group using a valid and reliable instrument. In our study, a significant association was observed between psychological morbidity and age with patients of age up to 40 years having a higher likelihood of suffering from depression and anxiety. This is in agreement with previous studies demonstrating that younger people are more prone to psychological distress when suffering from cancer $[31,34,35]$.

There was no statistically significant relationship between depression, anxiety and various demographic factors in the present study. A meta-analysis of $58 \mathrm{stu}-$ dies showed that there were significant differences among groups with regards to sex, age and type of cancer [36]. We, however, did not find any significant effect of gender on predisposition to psychological morbidity. Marital status, locality, education, income, and occupation also did not affect psychological morbidity presence in our study. In addition, there was no significant association of depression and anxiety with cancer type, duration, treatment, or surgery related to disease. A study from Japan, however, reported increased levels of depression in cancer patients undergoing surgery [37].

Strengths of our study include standardized measures, use of control group, analysis of factors that may affect prevalence of depression and anxiety and a good response rate. The goal of unbiased control was achieved by recruiting both cases and controls at the same time and under same conditions. Furthermore, both the cases and controls were from the same source population and were evaluated using the same instrument. We used a valid and reliable questionnaire developed indigenously in Urdu to reduce the potential of error caused by instruments developed from populations belonging to different cultural and socioeconomic setups. The study also has certain limitations including use of self reported questionnaires instead of diagnostic interview and unavailability of diagnosis for the control group.

In order to provide optimum care for cancer patients incorporating management of physical as well as psychological symptoms, it is necessary to increase awareness about prevalence of psychological morbidity among cancer patients and improve identification of symptoms [9]. It is recommended that all the cancer patients should complete a psychological screening on baseline as a part of standard cancer care. The oncologist should then refer the patients for appropriate care on the basis of results of screening. The concern expressed by some clinicians of bothering patients is unfounded as most of the patients are thankful for the opportunity to answer questions about their feelings [38]. It has been demonstrated that even a short psychological intervention delivered by nonspecialist is effective and promotes adjustment among cancer patients at a high risk of developing depression and anxiety [26,39]. This has also 
been recommended by NCCN clinical practice guidelines which recommend screening of patients for distress and psychotherapy subsequently for those with moderate to severe distress $[2,40]$.

\section{Conclusions}

The study shows that compared with control group, adults with cancer have higher prevalence rates of depression and anxiety. Younger age was associated with a higher likelihood of meeting criteria for psychological morbidity. The findings support screening patients for symptoms of depression and anxiety as part of standard cancer care and referring those at a higher risk of developing psychological morbidity for appropriate care. This will lead to decreased morbidity, improvement in disease outcome, reduction in healthcare costs, and improvement in quality of life of patients.

\section{List of Abbreviations}

SCID: Structured Clinical Interview for DSM Disorders; NCCN: National Comprehensive Cancer Network; Rs: Rupees.

\section{Acknowledgements}

We would like to thank Dr. Rab Nawaz Maikan and Dr. Durr-e-Sabih for their help and guidance in carrying out the study.

\section{Author details}

'Department of Medicine, Nishtar Medical College Hospital, Multan, Pakistan. ${ }^{2}$ Department of Radiotherapy and Oncology, Nishtar Medical College Hospital, Multan, Pakistan.

\section{Authors' contributions}

NAJ conceived and designed the study, participated in data acquisition, analyzed the data and drafted the manuscript. WM participated in data collection, analysis of data and reviewing of manuscript. MAS collected data and helped in data analysis and revision of final draft of manuscript. ZSC contributed to data collection and analysis. All authors read and approved the final manuscript.

\section{Competing interests}

The authors declare that they have no competing interests.

Received: 25 June 2010 Accepted: 29 October 2010 Published: 29 October 2010

\section{References}

1. Pirl WF: Evidence report on the occurrence, assessment, and treatment of depression in cancer patients. J Natl Cancer Inst Monogr 2004, 32:32-9.

2. National comprehensive cancer network (NCCN): Standards of care and management of distress penal. Distress management version 12007.

3. Zabora J, BrintzenhofeSzoc K, Curbow B, Hooker C, Piantadosi S: The prevalence of psychological distress by cancer site. Psychooncology 2001, 10(1):19-28.

4. Massie MJ: Prevalence of depression in patients with cancer. J Nat/ Cancer Inst Monogr 2004, 32:57-71.

5. Powe BD, Finne R: Cancer fatalism: the state of the science. Cancer Nurs 2003, 26:454-465.

6. Mystakidou K, Tsilika E, Parpa E, Katsouda E, Galanos A, Vlahos L: Assessment of anxiety and depression in advanced cancer patients and their relationship with quality of life. Qual Life Res 2005, 14:1825-33.

7. Costantin M, Musso M, Viterboli P: Detecting psychological distress in cancer patients: validity of the Italian version of the Hospital Anxiety and Depression Scale. Support Care Cancer 1999, 7:121-127.
8. Montazeri A, Milroy R, Hole D, McEwean J, Gills CR: Anxiety and depression in patients with lung cancer before and after diagnosis: findings from a population in Glasgow, Scatland. J Epidemiol Community Health 1998, 52:203-204.

9. Lloyd-Williams M: Difficulties in diagnosing and treating depression in the terminally ill cancer patient. Postgrad Med J 2000, 76:555-8.

10. Lynch ME: The assessment and prevalence of affective disorders in advanced cancer. J Palliat Care 1995, 11:10-8.

11. Donovan KA, Jacobsen PB: Fatigue, depression, and insomnia: evidence for a symptom cluster in cancer. Semin Oncol Nurs 2007, 23:127-35.

12. Hirschfeld RMA: Comorbidity of major depression and anxiety disorders: recoginition and management in primary care. Primary Care Companion J Clin Psychiatry 2001, 3:244-254.

13. Jacobsen PB, Jim HS: Psychosocial interventions for anxiety and depression in adult cancer patients: achievements and challenges. $C A$ Cancer J Clin 2008, 58:214-30.

14. Pandey M, Sarita GP, Devi N, Thomas BC, Hussain BM, Krishnan R: Distress, anxiety, and depression in cancer patients undergoing chemotherapy. World J Surg Oncol 2006, 4:68

15. Capuron L, Ravaud A, Dantzer R: Early depressive symptoms in cancer patients receiving interleukin 2 and/or interferon alfa-2b therapy. J Clin Oncol 2000, 18:2143-51.

16. Keller M, Sommerfeldt S, Fischer C, Knight L, Riesbeck M, Löwe B, Herfarth $C$, Lehnert T: Recognition of distress and psychiatric morbidity in cancer patients: a multi-method approach. Ann Oncol 2004, 15:1243-9.

17. Singer $\mathrm{S}$, Bringmann $\mathrm{H}$, Hauss J, Kortmann RD, Köhler U, Krauss $\mathrm{O}$, Schwarz R: Prevalence of concomitant psychiatric disorders and the desire for psychosocial help in patients with malignant tumors in an acute hospital. Dtsch Med Wochenschr 2007, 132:2071-6.

18. Pinquart M, Duberstein PR: Depression and cancer mortality: a metaanalysis. Psychol Med 2010, 40(11):1797-810.

19. Satin JR, Linden W, Phillips MJ: Depression as a predictor of disease progression and mortality in cancer patients: a meta-analysis. Cancer 2009, 115(22):5349-61.

20. O'Mahony S, Goulet J, Kornblith A, Abbatiello G, Clarke B, Kless-Siegel S, Breitbart W, Payne R: Desire for hastened death, cancer pain and depression: report of a longitudinal observational study. J Pain Symptom Manage 2005, 29:446-57.

21. Bui QU, Ostir GV, Kuo YF, Freeman J, Goodwin JS: Relationship of depression to patient satisfaction: findings from the barriers to breast cancer study. Breast Cancer Res Treat 2005, 89(1):23-8.

22. Spiegel D, Giese-Davis J: Depression and cancer: mechanisms and disease progression. Biol Psychiatry 2003, 54(3):269-82.

23. Frick $E$, Tyroller M, Panzer M: Anxiety, depression and quality of life of cancer patients undergoing radiation therapy: a cross-sectional study in a community hospital outpatient centre. Eur J Cancer Care (Engl) 2007, 16:130-6.

24. Ahn SH, Park BW, Noh DY, Nam SJ, Lee ES, Lee MK, Kim SH, Lee KM, Park SM, Yun YH: Health-related quality of life in disease-free survivors of breast cancer with the general population. Ann Oncol 2007, 18:173-82.

25. Grov EK, Dahl AA, Moum T, Fosså SD: Anxiety, depression, and quality of life in caregivers of patients with cancer in late palliative phase. Ann Oncol 2005, 16:1185-91.

26. Uitterhoeve RJ, Vernooy $M$, Litjens M, Potting $K$, Bensing J, De Mulder $P$ van Achterberg T: Psychosocial interventions for patients with advanced cancer-a systematic review of the literature. $\mathrm{Br} J$ Cancer 2004, 91:1050-1062.

27. Carlson LE, Bultz BD: Benefits of psychosocial oncology care: Improved quality of life and medical cost offset. Health and Quality of Life Outcomes 2003, 1:8.

28. Dogar IA, Azeem MW, Kiran M, Hussain I, Mehmood K, Hina I: Depression and anxiety in cancer patients in outpatient department of a tertiary care hospital in Pakistan. Pak J Med Sci 2009, 25(5):734-737[http://pjms. com.pk/issues/octdec109/article/article6.html].

29. Ali BS, Reza H, Khan MM, Jehan I: Development of an indigenous screening instrument in Pakistan: the Aga Khan University Anxiety and Depression Scale. J Pak Med Assoc 1998, 48:261-5.

30. Ahmer S, Faruqui RA, Aijaz A: Psychiatric rating scales in Urdu: a systematic review. BMC Psychiatry 2007, 7:59. 
31. Tavoli A, Mohagheghi MA, Montazeri A, Roshan R, Tavoli Z, Omidvari S: Anxiety and depression in patients with gastrointestinal cancer: does knowledge of cancer diagnosis matter? BMC Gastroenterol 2007, 7:28.

32. Demyttenaere K, Bruffaerts R, Posada-Villa J, Gasquet I, Kovess V, Lepine JP, Angermeyer MC, Bernert S, de Girolamo G, Morosini P, Polidori G, Kikkawa T, Kawakami N, Ono Y, Takeshima T, Uda H, Karam EG, Fayyad JA, Karam AN, Mneimneh ZN, Medina-Mora ME, Borges G, Lara C, de Graaf R, Ormel J, Gureje O, Shen Y, Huang Y, Zhang M, Alonso J, Haro JM, Vilagut G, Bromet EJ, Gluzman S, Webb C, Kessler RC, Merikangas KR, Anthony JC, Von Korff MR, Wang PS, Brugha TS, Aguilar-Gaxiola S, Lee S, Heeringa S, Pennell BE, Zaslavsky AM, Ustun TB, Chatterji S, WHO World Mental Health Survey Consortium: Prevalence, severity, and unmet need for treatment of mental disorders in the World Health Organization World Mental Health Surveys. JAMA 2004, 291(21):2581-90.

33. Mirza I, Jenkins R: Risk factors, prevalence, and treatment of anxiety and depressive disorders in Pakistan: systematic review. BMJ 2004, 328:794.

34. Redeker NS, Lev EL, Ruggiero J: Insomnia, fatigue, anxiety, depression, and quality of life of cancer patients undergoing chemotherapy. Sch Inq Nurs Pract 2000, 14:275-90.

35. Matsushita T, Matsushima E, Maruyama M: Psychological state, quality of life, and coping style in patients with digestive cancer. Gen Hosp Psychiatry 2005, 27:125-32.

36. Van't Spijker A, Trijsburg RW, Duivenvoorden HJ: Psychological sequelae of cancer diagnosis: a meta-analytical review of 58 studies after 1980. Psychosom Med 1997, 59:280-93.

37. Matsushita T, Matsushima E, Maruyama M: Anxiety and depression of patients with digestive cancer. Psychiatry Clin Neurosci 2005, 59:576-83.

38. Singer S, Kuhnt S, Götze H, Hauss J, Hinz A, Liebmann A, Krauss O, Lehmann A, Schwarz R: Hospital anxiety and depression scale cutoff scores for cancer patients in acute care. Br J Cancer 2009, 100:908-12.

39. Pitceathly C, Maguire P, Fletcher I, Parle M, Tomenson B, Creed F: Can a brief psychological intervention prevent anxiety or depressive disorders in cancer patients? A randomised controlled trial. Ann Oncol 2009, 20:928-34.

40. NCCN practice guidelines for the management of psychosocial distress. National Comprehensive Cancer Network. Oncology (Williston Park) 1999, 13:113-47.

\section{Pre-publication history}

The pre-publication history for this paper can be accessed here: http://www.biomedcentral.com/1471-2407/10/594/prepub

\section{doi:10.1186/1471-2407-10-594}

Cite this article as: Jadoon et al: Assessment of depression and anxiety in adult cancer outpatients: a cross-sectional study. BMC Cancer 2010 10:594.

\section{Submit your next manuscript to BioMed Central and take full advantage of:}

- Convenient online submission

- Thorough peer review

- No space constraints or color figure charges

- Immediate publication on acceptance

- Inclusion in PubMed, CAS, Scopus and Google Scholar

- Research which is freely available for redistribution 